\title{
Design and Analysis of a Compact UWB Band Notch Antenna for Wireless Communication ${ }^{+}$
}

\author{
Mohammad Monirujjaman Khan 1,* \\ 1 Department of Electrical and Computer Engineering, North South University, Bashundhara, Dhaka-1229, \\ Bangladesh; monirujjaman.khan@northsouth.edu \\ * Correspondence: monirujjaman.khan@northsouth.edu; Tel.: +8801779006296 \\ + Presented at the 1st International Electronic Conference-Futuristic Applications on Electronics,1-30 \\ November 2020; Available online:
}

Received: 17 September 2020; Accepted: 14 October 2020; Published: 30 October 2020

\begin{abstract}
Development and investigation of a miniaturized ultra-wideband band notch antenna is demonstrated in this paper. The antenna was modeled and simulated using Computer Simulation Technology (CST) ${ }^{\mathrm{TM}}$ Microwave Studio software. The simulated results of this antenna are presented and analyzed. The performance parameters such as return loss, gain, radiation efficiency, radiation patterns are simulation based results provided here. The main objective of this paper was to obtain band notch characteristics at the Wireless Local Area Network (5.15-5.8 GHz) and WiMax (5.25-5.85 GHz) in the UWB frequency ranges of 3.1 to $10.6 \mathrm{GHz}$ in order to avoid interference. Results and analysis show that the antenna meets the objective and shows very good results. It has very compact size as well which is attractive feature of this antenna that will make it suitable for ultra-wideband wireless communication systems.
\end{abstract}

Keywords: ultra-wideband antenna; band notch; wireless communications; CST; simulation; performance; return loss; gain; radiation efficiency; radiation pattern.

\section{Introduction}

Ultra-wideband (UWB) system is very promising technology for warless communications due its low transmission power, compact size, high data rate and large bandwidth [1]. This technology is an innovative wireless technology which is attracting researchers nowadays. For small period of UWB pulses, it is simple to persuade high data rate with small latency. The promising application of UWB is in sensor network, body area network, wireless positioning system, indoor short range communications, biomedical imaging, and high data rate small range communications [1-5]. Federal Communication Communications FCC declares UWB frequency range is to be from $3.1 \mathrm{GHz}$ to 10.6 $\mathrm{GHz}$ at $-10 \mathrm{~dB}$ return loss [2]. The issue is that in the wide frequency range there are other frequencies for Wireless Local Area Network (5.15-5.8 GHz) and WiMax (5.25-5.85 GHz) which may cause interference. Therefore in order to design interference less and power efficient wireless communications there is a need of band notch ultra-wideband antennas.

Antenna is one of the most important element for any wireless communication system. Therefore the antenna needs to meet the special requirement in terms of impedance bandwidth, return loss, radiation efficiency, gain and radiation pattern. A good antenna design gives relax to system designers. There is tremendous growing research and interest are realized for the design of UWB antennas recently [6-15]. In [6-11] UWB antenna design and radio channel modeling for wireless communication have been presented. Ultra-wideband band north antenna has been presented in open literature in [12-15]. However, different authors have use different techniques for band notch in UWB antennas. There is still no breakthrough for the design of UWB antenna with band notch yet. In [15] the presented band notch antenna is bigger in size. Some band notch antennas in open 
literatures are found to be bigger in size and some of them have low performances. In order to design compact, light weight, band notch characteristic and efficient system a compact antenna with band notch characteristic and good performance parameters are required.

In this paper a compact novel band notch antenna is designed and simulated. Simulated performance parameters like bandwidth, return loss, gain, efficiency and radiation efficiency have been illustrated and investigated.

\section{Antenna Design Using CST Software}

The proposed band notch UWB antenna was developed with the help of Computer Simulation Software (CST) microwave studio. In Figure 1 the antenna design is presented. Figure 1a demonstrate the front side and Figure $1 \mathrm{~b}$ provides the rear side of the antenna. In the backside of the antenna there is not full ground plane. It is noted that ground plane has been cut for getting the desired return loss result. The total length and width of the antenna are $16 \mathrm{~mm}$ and $25 \mathrm{~mm}$, respectively. For this design Fr4 substrate has been used with the relative permittivity of 3 . The radiation element of the antenna is printed on the substrate as shown in Figure 1. The antenna is excited with waveguide port. A slot was created on the radiating element to get the notch function. The whole height of the antenna is 1.8 $\mathrm{mm}$. The total size of the antenna is very compact.

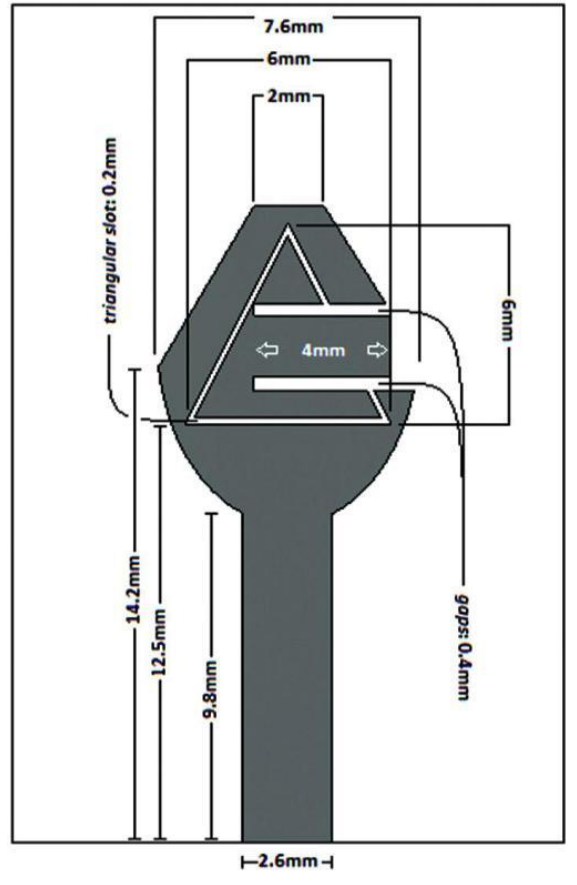

(a) Font view

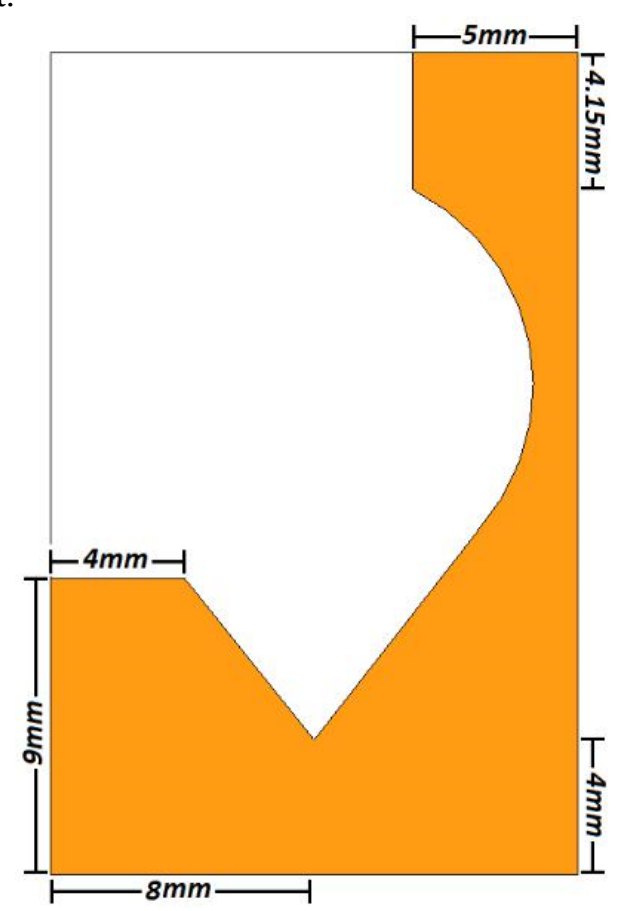

(b) Back view

Figure 1. band notch antenna: (a) front view, (b) back view.

\section{Results and Discussions}

After modeling the antenna in CST it was simulated. The simulated performance parameters such as return loss, gain, radiation pattern, and radiation efficiency are provided below.

\subsection{Simulated Return Loss Response}

Figure 2 displays the return loss result of the antenna. From the graph shown in Figure 2, it is noted that the antenna works at ultra-wideband frequency band $(3.1 \mathrm{GHz}$ to $10.6 \mathrm{GHz})$ except there is notch from 5.1 to $5.8 \mathrm{GHz}$. The main objective of this proposed design was to obtain the band notch characteristics at these frequencies in order to avoid interference with the frequency range from 5.1 to $5.8 \mathrm{GHz}$. The return loss results meet the expected objective of this paper. However at other frequency in the UWB range the return loss value is below $-10 \mathrm{~dB}$ which is excellent for power 
efficient transmission. As we know that return loss $-10 \mathrm{~dB}$ shows nearly $90 \%$ of the power will be transferred.

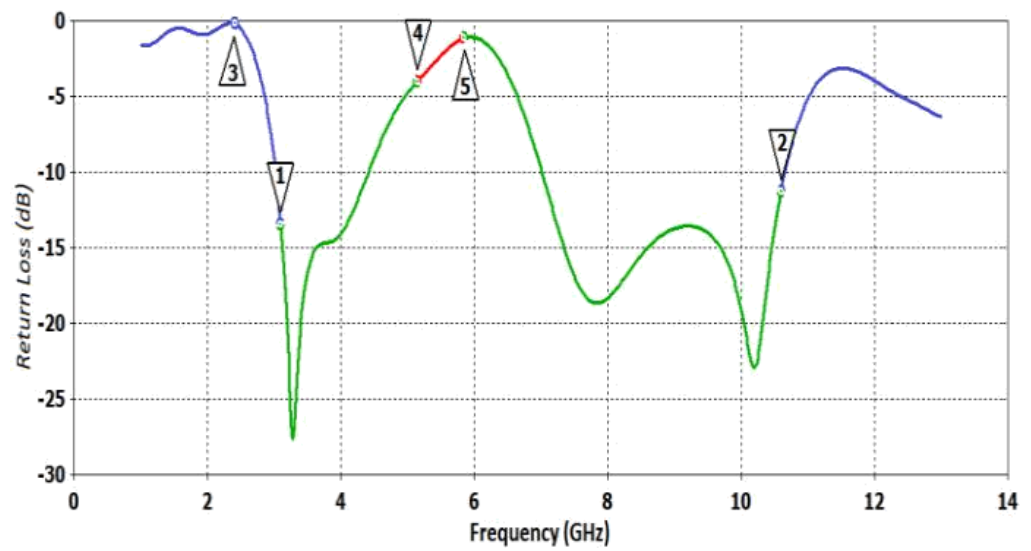

Figure 2. Return loss result of the antenna.

\subsection{Simulated Radiation Efficnecy and Gain}

The gain and radiation efficiency of this antenna are listed in Table 1 . The gain and radiation efficiency are extracted from the far field simulated results at the frequencies of $3.5 \mathrm{GHz}, 5.7 \mathrm{GHz}$ (band notch), $8 \mathrm{GHz}$ and $10 \mathrm{GHz}$. From the table it is noticed that the antenna demonstrates higher gain at $3.5 \mathrm{GHz}, 8 \mathrm{GHz}$, and $10 \mathrm{GHz}$ as compared with the $5.7 \mathrm{GHz}$. At $5.7 \mathrm{GHz}$ the gain is lower due to notch at this frequency and this is expected. For the case of radiation efficiency same trend is noticed. There is very low efficiency $38 \%$ at the $5.7 \mathrm{GHz}$ whereas other bands they show very good radiation efficiency.

Table 1. Values of gain and radiation efficiency at various frequencies.

\begin{tabular}{ccccc}
\hline Frequency $(\mathbf{G H z})$ & $\mathbf{3 . 5} \mathbf{~ G H z}$ & $\mathbf{5 . 7} \mathbf{~ G H z}$ & $\mathbf{8 ~ G H z}$ & $\mathbf{1 0 ~} \mathbf{~ H z}$ \\
\hline Gain $(\mathrm{dBi})$ & 1.65 & 0.72 & 2.40 & 2.35 \\
Radiation Efficiency $(\%)$ & 85.08 & 38.00 & 74.00 & 79.00 \\
\hline
\end{tabular}

\subsection{Simulated Radiation Patterns}

Simulated radiation patterns of the antenna are extracted from the far field at specific frequency. The radiation pattern is extracted from the $3 \mathrm{D}$ radiation of the antenna. Figures $3 \mathrm{a}-\mathrm{f}$ shows the simulated radiation patterns of the antenna at various frequencies. The radiation patterns have been plotted as plane wise like elevation and azimuth planes. At $3.5 \mathrm{GHz}$ the radiation pattern at $\mathrm{XY}$ plane looks omnidirectional and at XZ plane it looks there is a null at the $120^{\circ}$ angle. Both planes radiation patterns look similar at $5.7 \mathrm{GHz}$. At higher frequencies such as $8 \mathrm{GHz}$ and $10 \mathrm{GHz}$ the radiation patterns look little distorted at certain angle.

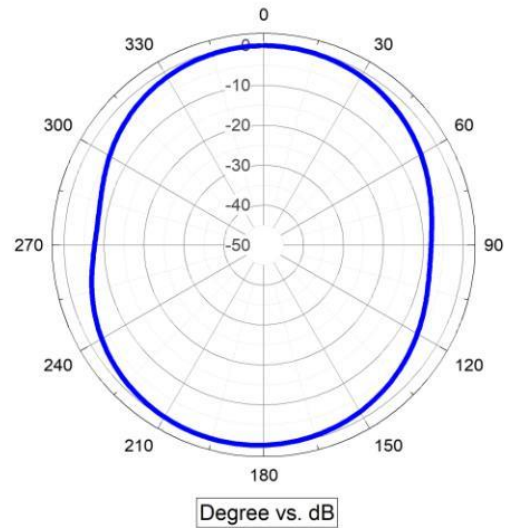

(a) XY Plane at $3.5 \mathrm{GHz}$

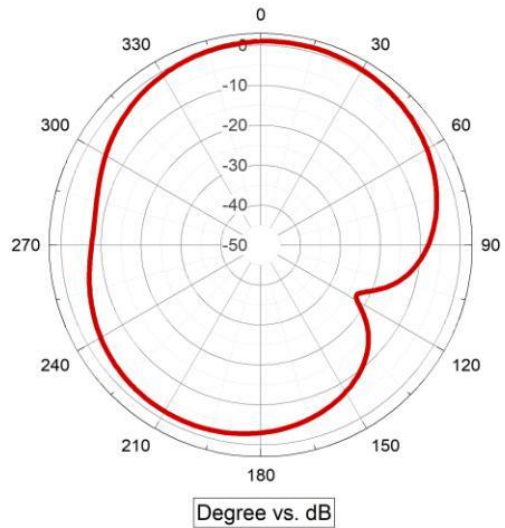

(b) XZ Plane at $3.5 \mathrm{GHz}$ 


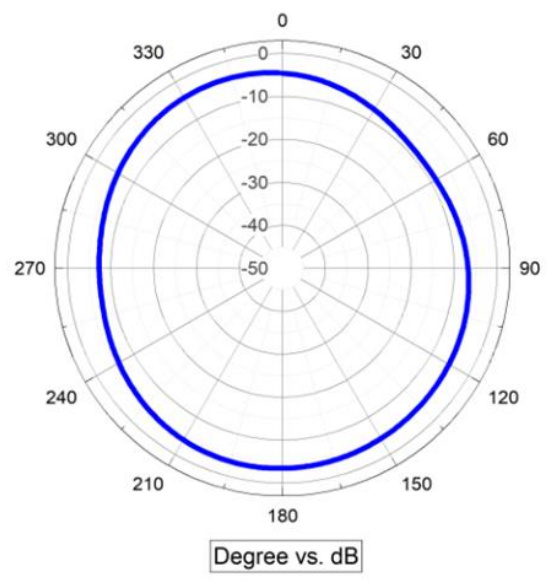

(c) XY Plane at $5.7 \mathrm{GHz}$

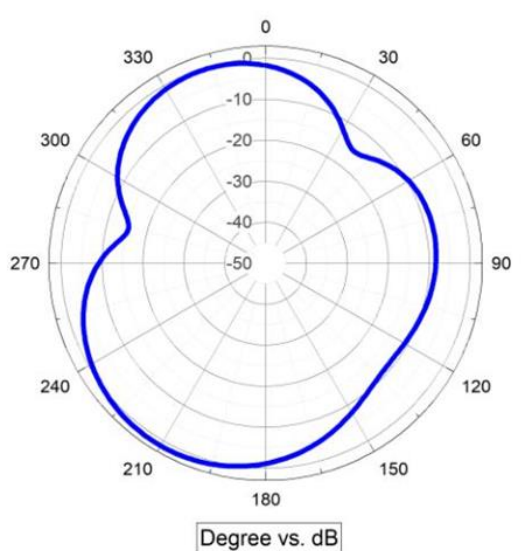

(e) $\mathrm{XY}$ Plane at $8 \mathrm{GHz}$

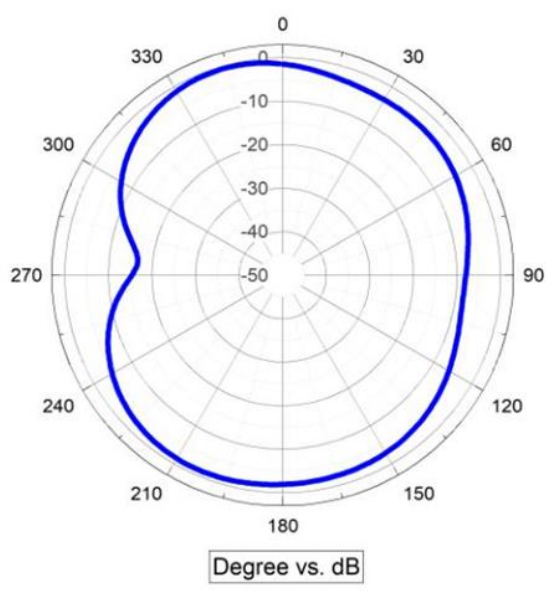

(g) XY Plane at $10 \mathrm{GHz}$

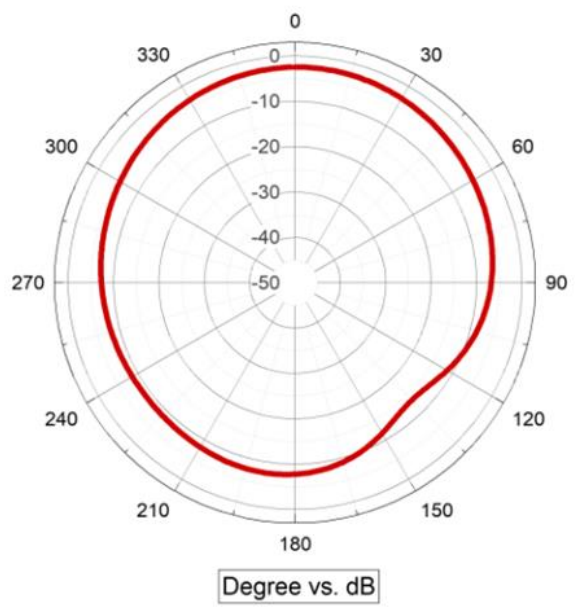

(d) XZ Plane at $5.7 \mathrm{GHz}$

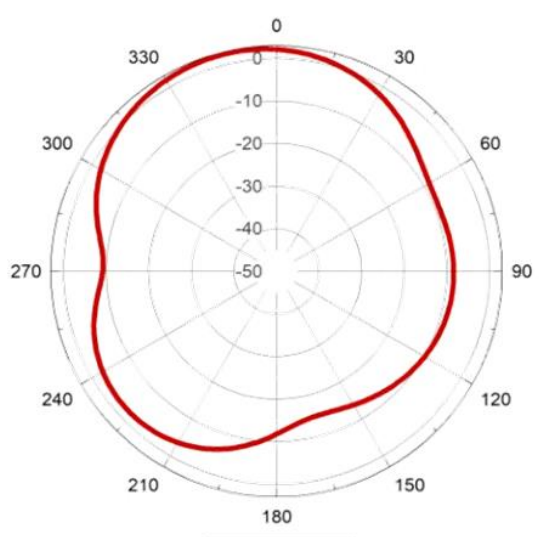

Degree vs. $\mathrm{dB}$

(f) XZ Plane at $8 \mathrm{GHz}$

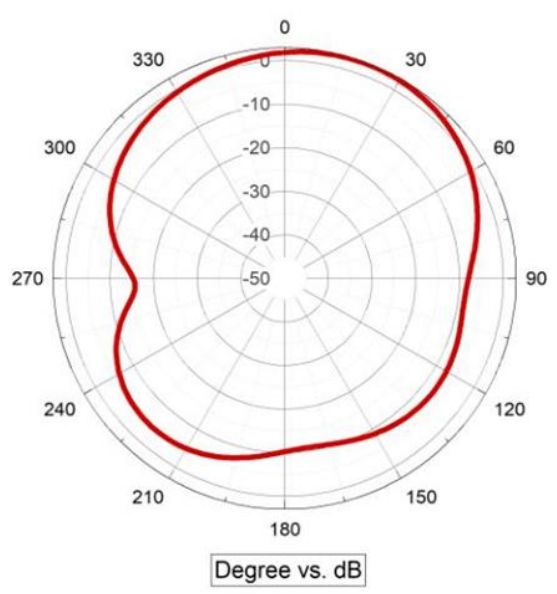

(h) XZ Plane at $10 \mathrm{GHz}$

Figure 3. Simulated radiation patterns of the antennas at various frequencies.

\subsection{Future Work}

This antenna will be fabricated and the performance will be measured and compared with the simulation results. CST software is very user friendly and it has been noticed for other articles cases [7-10] that the simulated results are comparable to the measured results. Parametric study of this antenna will be carried out and it will be designed also on the textile substrate to see the usability of this antenna for wearable applications. The on-body results of this textile antenna will be investigated. This future work is going on and due to lack of space here we have not demonstrated 
them. However, in future we will submit the extended version of this paper in a MDPI journal for review.

\section{Conclusion}

Software designed and simulation based performance of a compact novel UWB band notch antennas are provided. The antenna works in the FCC defined UWB frequency ranges $3.1 \mathrm{GHz}$ to 10.6 GHz perfectly with the band notch characteristic 5.1 to $5.8 \mathrm{GHz}$ with a view to avoid interference and power efficient wireless communications. At $5.7 \mathrm{GHz}$ the antenna demonstrated very bad results due to notch feature and that was the objective of this paper. However, except the band notch frequency this antenna shows very good results. At $3.5 \mathrm{GHz}, 6 \mathrm{GHz}, 8 \mathrm{GHz}$, and $10 \mathrm{GHz}$ the antenna shows very good efficiency and gain values. Due to compact and novel size, and very good results, band notch characteristic this antenna will be a suitable candidate for wireless communications.

Funding: The authors of this paper have not received any external fund for the work and results presented in this paper.

Acknowledgments: The work has been carried in the Department of Electrical and Computer Engineering at North South University. Authors would like to thank the ECE Department of North South University.

Conflicts of Interest: The authors declare no conflict of interest.

\section{References}

1. Hall, P.S. and Hao, Y. Antennas and Propagation for Body-Centric Wireless Communications, Artech House: Norwood, MA, USA, 2006.

2. Revision of part 15 of the Commission's rules regarding UWB transmission systems, Federal Communications Commission: Washington, DC, USA, April 2002

3. Ullah, S.; Ruan, C.; Sadiq, M.S.; Haq, T.U.; He, W. High Efficient and Ultra Wide Band Monopole Antenna for Microwave Imaging and Communication Applications. Sensors 2020, 20, 1-11.

4. Allen, G.O.B., Dohler, M., Okon, E., Malik,W.Q. A. K. Brown, and D. Edwards, UWB antenna and Propagation for Communications, Radar and Imaging. John Wiley and Sons: Hoboken, NJ, USA, 2007.

5. E. Staderini, UWB radars in medicine, IEEE Aerosp. Electron. Syst. Mag. 2002, 17, 13-18

6. Khan, M.M., Monsurul Alam, A.K.M, Kumer, P. Investigation of a Compact Ultra-wideband Antenna for Wearable Applications, Int. J. Commun. Antenna Propag. 2014, 4, 124-129.

7. Yeboah-Akowuah, B., Kosmas, P. and Chen, Y. A Q-Slot Monopole for UWB Body-Centric Wireless Communications, Int. J. Commun. Antenna Propag. 2017, 65, 5069-5075, doi: 10.1109/TAP.2017.2740977.

8. Khan, M.M., Mobin, I., Palikaras, G. and Kallos, E. Study of a small printed quasi-self complementary ultrawideband antenna for on-body applications. In Proceedings of the 2012 4th Computer Science and Electronic Engineering Conference (CEEC), Colchester, Essex, UK, 12-13 September 2012

9. Khan, M.M, Azizur Rahman, Md., Alomainy, A. and Parini, C. On-Body Radio Channel Performance of a Small Printed Quasi-Self-Complementary Ultra-wideband Antenna. In Proceedings of the 2nd International Conference on Advances in Electrical Engineering, (ICAEE-2013), Bashundhara, Dhaka, Bangladesh, 19-21 December 2013

10. Abbasi, Q.H., Khan, M.M., Liaqat, S., Kamran, Alomainy, M.A. and Hao, Y. Experimental Investigation of Ultra-wideband Diversity Techniques for On-body Radio Communications, Prog. Electromagn. Res. C 2013, 34, 165-181.

11. Khan, M.M., Abbasi, Q.H., Alomainy, A. and Parini, C. Experimental Investigation of Subject Specific OnBody Radio Propagation Channels for Body-Centric Wireless Communications. Electronics 2014, 3, $26-42$.

12. Abbas, A., Hussain, N., Jeong, M.J. Park, J., Shin, K.S., Kim, T. and Kim, N. A Rectangular Notch-Band UWB Antenna with Controllable Notched Bandwidth and Centre Frequency. Sensors 2020, 20, 777.

13. Mok, K.Y.; Rhee, Y.C.; Yoon, J.H. Design of a pot-shaped monopole antenna with dual band notched characteristics for UWB application. J. Electromagn. Eng. Sci. 2017, 17, 44-49.

14. Liu, H.-W., Ku, C.-H., Wang, T.-S. and Yang, C.-F. Compact Monopole Antenna with Band-Notched Characteristic for UWB Applications. IEEE Antennas Wirel. Propag. Lett. 2010, 9, 397-400.

15. Gheethan, A.A.; Anagnostou, D.E. Dual band-reject UWB antenna with a sharp rejection of narrow and closely-spaced bands. IEEE Trans. Microwave Theory Tech. 2012, 60, 2071-2076. 
( 2020 by the authors. Submitted for possible open access publication under the terms and conditions of the Creative Commons Attribution (CC BY) license (http://creativecommons.org/licenses/by/4.0/). 